\title{
Assessment of Mosquito Diversity and Plasmodium falciparum in Female Anopheles Mosquito in Students' Hostels, Ahmadu Bello University Zaria, Kaduna State Nigeria
}

\author{
${ }^{* 1}$ A.A. Rice, ${ }^{1}$ C.E. Mbah, ${ }^{2}$ B.D.J. George \\ ${ }^{1}$ Department of Zoology, \\ Faculty of Life Sciences, \\ Ahmadu Bello University, \\ Zaria, Nigeria
}

${ }^{2}$ Department of Veterinary Parasitology and Entomology, Faculty of Veterinary Medicine, Ahmadu Bello University, Zaria, Nigeria

Email: aishatuabdullahirice@gmail.com

\begin{abstract}
Mosquitoes are considered as the most important insect vectors of many infectious disease agents, whose presence pose a serious public health concern within localities where they are found especially in tertiary institution. The study was conducted to identify mosquito species and Plasmodium falciparum in female Anopheles mosquito in students' hostels of Ahmadu Bello University. Mosquitoes were caught once in a week for five months June to October (2018), by the used of test tube, chloroform and cotton wool. A total of 1341 mosquito vectors was identified, comprising four (4) species: Anopheles gambiae complex, Anopheles funestus, Culex quinquefasciatus and Aedes aegypti. The mosquitoes were dissected transversely between the first and third pairs of legs under the dissecting microscope The entire samples were air dried, fixed in methanol and were stained using Giemsa and thin blood film examined under the light microscope for identification of Plasmodium falciparum. The result in this study showed that Culex quinquefasciatus constitutes the most abundant with 950 (59\%) followed by Anopheles gambiae 370, (22\%), and An. funestus 15(0.9\%) while Aedes aegypti 3(0.1\%) had the least. Of the two species of anophelene mosquitoes encountered in this study only Anopheles gambiae was positive for Plasmodim falciparum. The result simply showed that efforts to control malaria especially in Zaria area should be a combination of existing methods which is usually referred to as integrated control.
\end{abstract}

Keywords: Mosquito, Plasmodium falciparum, Anopheles, Hostels

\section{INTRODUCTION}

Plasmodium falciparum is a protozoan parasite that causes an infectious disease known as malaria, and is the most severe strain of the malaria species responsible for malarial death 
(CDC, 2015). This parasite is responsible for most of the complications (Black water fever, gastrointestinal disturbance, hyperpyrexia, and hypoglycemia in pregnant women) associated with human malaria (Bechemagbor, 2010). The other 3 species that cause malaria include: P. vivax, P. ovale, and P. malariae.

Malaria is considered to be one of the most severe infectious diseases worldwide, causing about half a million deaths every year, primarily in the developing world (WHO, 2016). More than two-thirds of malaria deaths globally is found in children under 5 years of age. About 3.2 billion people (almost half of the world's population) are at risk of malaria (WHO/UNICEF, 2015). Fifteen countries mainly in sub-Saharan Africa, accounted for $80 \%$ of cases and 78\% of deaths globally in 2015 (WHO/UNICEF, 2015). It is transmitted by Plasmodium-infected female Anopheline mosquitoes.

The disease (malaria) can be attributed almost entirely to some mosquito species namely: Anopheles gambiae, An. arabiensis and An. funestus, which are three of the most efficient malaria vectors in the world (Collins and Besansky, 1994). All live almost exclusively in close association with humans and feed on blood, primarily from humans (Collins and Besansky, 1994).

Mosquitoes belong to the order Diptera, Family Culicidae and Subfamily Culicinae. They are characterized by having long conspicuous needle-shaped mouthparts comprising the proboscis which, in the female, is used for sucking blood (W.H.O., 2014). There are about 3,100 known species of mosquitoes (Abubakar, 2014), which are separated into two great divisions - the Anophelines and Culicines. The Anophelines being the smaller division, but includes the vectors of human malaria and filariasis. The Culicines include vectors of viral and filarial diseases of man (Service, 1980).

Mosquitoes are unambiguously the most important vectors of infectious disease-causing agents that tremendously affect global health, with over half of the global human population at risk of exposure to mosquito-transmitted infections (Tolle, 2009) and more than 1 billion cases of such infections are reported each year (W.H.O., 2014).

Anopheles mosquitoes constitute various species with peculiar behaviour associated with their biting activities and malaria transmission (Oyewole et al., 2007; Nwosu et al., 2011). Large number of Anopheles species have been reported in Nigeria, but the world's most efficient vectors of human malaria belong to members of Anopheles gambiae sensu lato (s.l.) complex and An. funestus complexes (Oyewole et al., 2007). An. gambiae s.l. is a complex of eight sibling species, which presently includes An. gambiae (sensu stricto) Giles; An. arabiensis Patton; An. bwambae White; An. melas Theobald; An. merus Dönitz; An. quadriannulatus Theobald; An. amharicus Hunt, Coetzee and Fettene and An. comorensis Brunhes, le Goff and Geoffroy (Obembe and Awopetu, 2014). These sibling species are morphologically identical, but genetically distinct. The two members of the An. gambiae complex most responsible for transmission of malaria, An. gambiae s.s. and An. arabiensis, are broadly sympatric, although the latter is more broadly distributed in arid regions (De Souza et al., 2010; Levineet al., 2004). The range and relative abundance of An. arabiensis and An. gambiae s.s. appear to be strongly influenced by climatological factors especially total annual precipitation (Onyabe and Conn, 2001). Tropical areas including Nigeria have the best combination of adequate rainfall and humidity allowing for breeding and survival of anopheline mosquitoes (Ayanda, 2009). Therefore, malaria could be the largest contributor to total disease burden and productivity losses resulting from major tropical diseases in the country. Demography 
as well as the socio-economic and cultural characteristic of the population, the predominant vectors and parasites play vital role in the sustenance of malaria burden in the country. In Nigeria, malaria is endemic and stable, being a major cause of morbidity and mortality, resulting in $25 \%$ infant and $30 \%$ childhood mortality (FMH, 2013).

Prevention of malaria is best achieved by vector control, which today in Africa relies on the use of insecticides. Monitoring mosquito vector populations is an integral and essential component of most vector control programmes. Contemporary data on mosquito species composition, resistance to insecticides, and actual infection status of mosquito vectors are a prerequisite for GCeffective interventions (Vontas, 2016). Malaria control methods focus largely on impacting the vector population to reduce transmission. Interventions such as use of indoor residual spray (IRS) and long-lasting insecticidal nets, take advantage of speciesspecific vector behaviors that result in exposure to lethal insecticide (Bayoh et al., 2014).

Knowledge of mosquitoes diversity and abundance in students' hostel will provide information on the health implications and effective strategies against mosquito-borne diseases.

Furthermore, the understanding the transmission status of Plasmodium parasite by Anopheline mosquitoes in students' hostel will provide useful information to the health authorities on proper measures in case of malaria outbreak.

\section{MATERIALS AND METHODS}

\section{Study area}

The study was carried out in Ahmadu Bello University Zaria, Kaduna state. Zaria is situated at Latitude $11^{\circ} 25^{\prime}$ North and Longitude $4^{\circ} 27^{\prime}$ East of Nigeria. Zaria is located in the North Western part of Nigeria.

\section{Collection of Mosquitoes}

Two blocks were randomly selected from each of the male and female halls, Mosquitoes were collected indoors using the method of Mbah and Egidenda, 2007. The open end of a test tube measuring $10 \mathrm{~cm}$ in length by $1.4 \mathrm{~cm}$ in diameter was placed over the resting mosquito and slightly moved to enable the mosquito fly into the tube. A piece of cotton wool lightly soaked with chloroform was used to plug the mouth of the test tube. The dead mosquitoes were then transferred gently into a Petri dish, clearly labelled indicating the date and site of collection. The mosquitoes collected were then transported to the Entomology laboratory Department of Zoology, Ahmadu Bello University Zaria for identification.

Consecutive indoor collections of indoor resting mosquitoes were carried out in each location once in a week during the rainy seasons between June and October, 2018.

\section{Morphological Identification}

The mosquitoes were identified morphologically with the aid of a light microscope at $x 20$ and x40 magnification using the identification keys of Gilles and Coetzee (1987) and Gillies and De-mellion (1968).

\section{Dissection of Mosquitoes}

The engorged female Anopheles mosquito was dissected transversely between the first and third pairs of legs under the dissecting microscope; Each abdomen was cut off using sterile tips. The entire samples were air dried, fixed in methanol and were stained for 15-30 
minutes using Giemsa and thin blood film examined under the light microscope using $\times 100$ objective lens as described by Cheesbrough, (2009).

\section{Data Analyses}

Two diversity indices, Shannon-Wieners $(\mathrm{H})$, and Evenness $(\mathrm{E})$, were used to determine the mosquitoes species diversity. Principal Component Analysis (PCA) Biplot was used to correlate the relationship of mosquitoes diversity, relative abundance, location and prevalence of Plasmodium parasite

\section{RESULTS AND DISCUSSION}

A total of 1341 mosquitoes were collected in 6 students' hostels from June to October 2018. They were classified into four genera and four species the highest number of individual mosquitoes were recorded from Akenzua (320) while the least was from Amina (161). Among the individual female mosquitoes caught in hostels. Akenzua 135(36.49\%) had the highest number of Anopheles gambiae while Ribadu 22 (5.95\%) had the least (Table 1). In ICSA, 7 (46.67\%) Anopheles funestus which formed the highest collection of this species were recorded, followed by Akenzua and Suleiman where 4 (26.67\%) were recorded. Akenzua 179 $(19.67 \%)$ had the highest Culex quinquefascitus while Amina had the least 124 (13.05\%). Aedes aegypti was recorded the highest in Akenzua $2(66.67 \%)$ while Suleiman had the least 1 $(33.33 \%)$. In terms of Shannon diversity Akenzua, ICSA/Ramat and Suleiman Hostel were recorded the moderate 1.05, 1.07 and 1.05 respectively while Amina, 0.85, Danfodio, 0.89 and Ribadu, 0.77 showed lower species diversity. The evenness of species distribution of Akenzua, Amina, Danfodio, ICSA/Ramat hall, Ribadu and Suleiman were found to be 0.57, $0.78,0.81,0.73,0.72$ and 0.57 respectively.

Table 1: Overall Species Distribution of Mosquitoes in Students Hostels Ahmadu Bello University, Zaria

\begin{tabular}{lllllll}
\hline & \multicolumn{5}{c}{ Locations (Halls) } \\
\hline Species & Akenzua & Amina & Danfodio & ICSA/Ramat & Ribadu & Suleiman \\
An. gambiae & $135(36.49)$ & $33(8.92)$ & $30(8.11)$ & $88(23.78)$ & $22(5.95)$ & $62(16.76)$ \\
An. funestus & $4(26.67)$ & $0(0.00)$ & $0(0.00)$ & $7(46.67)$ & $0(0.00)$ & $4(26.67)$ \\
Cx. quinquefasciatus & $179(18.34)$ & $128(13.05)$ & $166(17.01)$ & $170(17.42)$ & $170(17.89)$ & $141(14.45)$ \\
Ae. aegypti & $2(66.67)$ & $0(0.00)$ & $0(0.00)$ & $0(0.00)$ & $0(0.00)$ & $1(33.33)$ \\
Abundance & 320 & 161 & 196 & 264 & 192 & 208 \\
Shannon_H & 1.05 & 0.85 & 0.89 & 1.07 & 0.77 & 1.05 \\
Evenness_e^ $\mathrm{H} / \mathrm{S}$ & 0.57 & 0.78 & 0.81 & 0.73 & 0.72 & 0.57 \\
\hline
\end{tabular}

A total of 810 blood-fed mosquitoes were caught in students hostels in Ahmadu Bello University, Zaria (Table 2). The distribution of individual female mosquitoes caught in the hostel were as follows: Culex quinquefasciatus were recorded the highest number of blood-fed 591(60.55) followed by An. gambiae s.s 210(56.75), An. funestus 8(53.33) while Aedes aegypti had the least 1(33.33). The number of unfed mosquitoes recorded indicate that Culex quinquefasciatus had the highest 359(36.78) while Aedes aegypti had the least 2(66.66). 
Table 2: Species Distribution of Blood-fed and unfed Mosquitoes in Students hostels, A.B.U

\begin{tabular}{llcc}
\hline Species & Total No. examined & Blood fed (\%) & Unfed (\%) \\
\hline An. gambiae & 370 & $210(56.75)$ & $160(43.24)$ \\
An. funestus & 15 & $8(53.33)$ & $7(46.66)$ \\
Cx. quinquefasciatus & 950 & $591(60.55)$ & $359(36.78)$ \\
Ae. aegypti & 3 & $1(33.33)$ & $2(66.66)$ \\
\hline Total & 1338 & $810(60.53)$ & $528(39.46)$ \\
\hline
\end{tabular}

The Relative abundance of mosquitoes in students hostels is shown in (Fig.1) $C x$. quinquefasciatus recorded the highest (59.12) followed by An. gambiae s.s (22.47), An. funestus (0.91) while Ae.aegypti had the least (0.18)

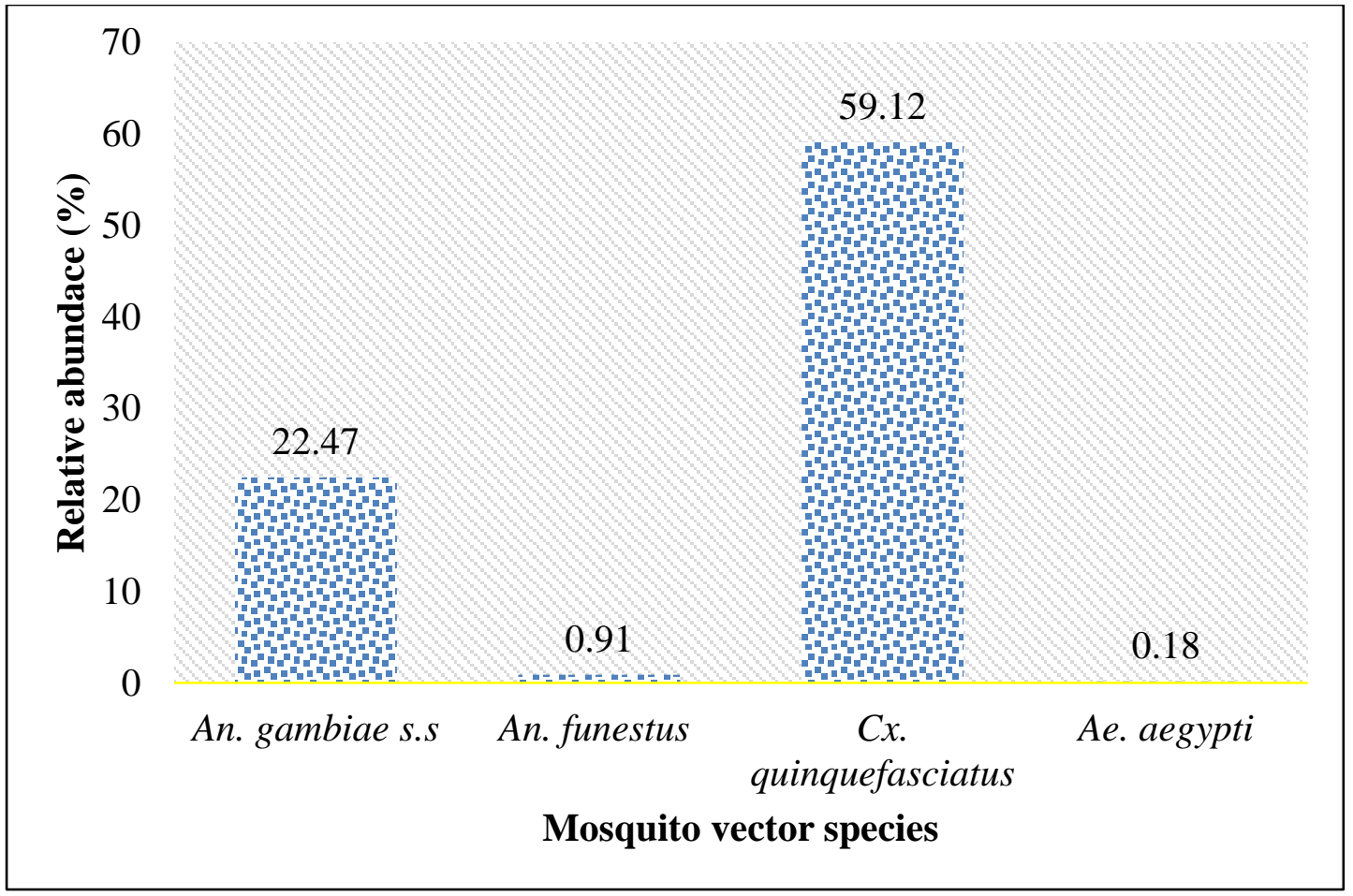

Figure 1: Relative Abundance of Mosquito Species in students hostels Ahmadu Bello University

A total of 60 blood-fed female Anopheles mosquitoes were examined in this study. Plasmodium falciparum was encountered and ICSA/Ramat (7) had the highest number of infected mosquitoes while Danfodio had 2(28.54) 
Table 3: Malaria parasite in blood-fed Mosquitoes

\begin{tabular}{lll}
\hline & No examined & Prevalence (\%) \\
\hline \multirow{2}{*}{ Akenzua } & 12 & P. falciparum \\
Amina & 12 & $3(41.67)$ \\
Danfodio & 7 & $2(25)$ \\
ICSA/Ramat & 12 & $7(58.33)$ \\
Ribadu & 5 & $0(0)$ \\
Suleiman & 12 & $4(33.33)$ \\
\hline TOTAL & 60 & $21(35.00)$ \\
\hline
\end{tabular}

The first component had the highest possible variance (64.49). An. gambiae, An. funestus, Ae.aegypti, and Cx. quinquefasciatus were positively correleted with Akenzua, ICSA/Ramat and Suleima hostels, Plasmodium falciparum are associated with Suleiman hostel. The Evenness of species distribution were negatively correlated with Amina hostel, Danfodio hostel and Ribadu hostel (27.76) as seen in fiqure 2

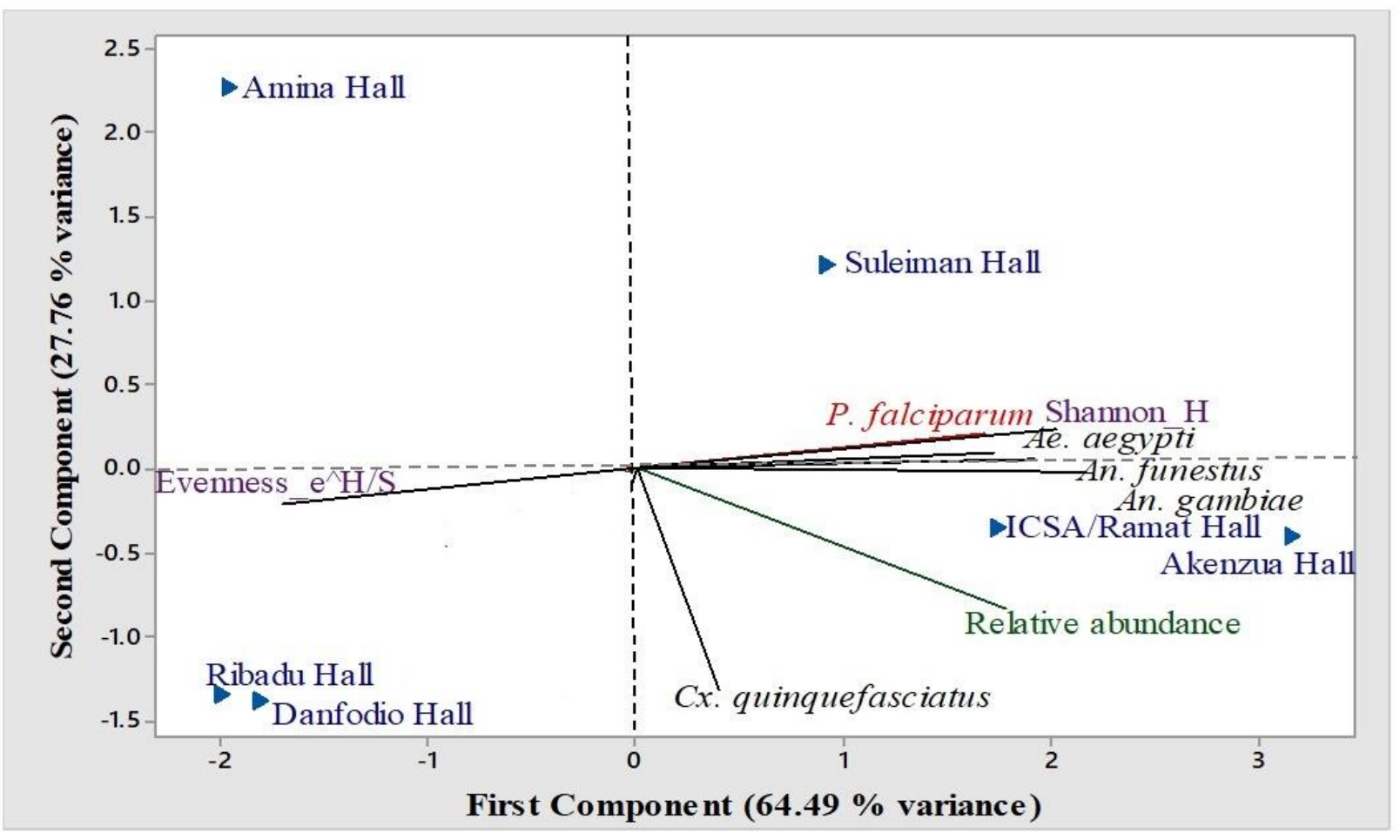

Figure 2: Principal component analysis (Biplots) of mosquito diversities, evenness, their relative abundance and plasmodium parasites detected in students' halls, Ahmadu Bello University, Zaria, Nigeria 


\section{DISCUSSION}

The dominant species identified were Culex quinquefasciatus, and Anopheles gambiae collected in all the six student hostels while the others like Anopheles funestus were less frequent. Aedes aegypti were present only in Akenzua and Suleiman hostels. This could be as a result of the presence of collections of dirty water in sample locations which serve as their breeding grounds. Similarly, the surrounding bushes around the various residential hostels which include tufts of grass and other emergent vegetation which could serve as their resting places, this could be responsible for large number observed. These findings agree with the report of Michael (2014) who reported the presence of similar species of mosquitoes in Zaria dam in which Culex quinquefasciatus and Anopheles gambiae were the most dominant. This is in line with the study of Adeleke et al., (2010) who recorded Culex quinquefasciatus to be the second predominant species of mosquitoes occurring in Abeokuta.

The proportion of Anopheles gambiae and Culex quinquefasciatus with blood were higher than the others namely : An. funestus, and Ae. aegypty. The high percentage of blood-fed mosquitoes clearly shows that the two genera are not just endophagic, but also endophilic as they were caught while resting indoors. This is not surprising as both species are anthropophilic. This finding was observed by Ebenezer et al., (2012) during his similar study in some part of Bayelsa State. And Adeleke et al., (2010) in Abeokuta. The preponderance of blood-fed mosquitoes over the unfed ones is a positive indication that man-biting mosquitoes are active in the halls with the subsequent transmission of the parasites they carry and resultant diseases being spread within the student population.

Culex quinquefasciatus, have the widest range of distribution and formed the dominant species in this study. This could be due to the fact that the culex species are known to breed in polluted water. Water storage containers and ground collection of dirty water were observed around the hostels which may increase the breeding ground.

Two species of Anopheles were caught: Anopheles gambiae and Anopheles funestus. Anopheles gambiae constitute the highest out of the two Anopheles species sampled which was also the second most abundant species caught during the sampling after Culex quinquefasciatus. This observation can be explained in the light of the fact that generally, An. gambiae complex are associated with human beings and therefore tend to enter the hostels and breed in water collections within the vicinity. Another reason could be associated with their feeding and resting habits where An. gambiae complex is known to be anthropophilic. Anopheles funestus was in relatively low proportion and this may be due to the fact that it breeds in more permanent large water bodies like rivers and lakes (Ndams, 2004). These findings agrees with the report of Ayanda (2009), who recorded more than half of An. gambiae and to a lesser extent Anopheles funestus which are commonly reported malaria vectors in Nigeria.

Aedes aegypti were in relatively low proportion in this study, and this may be due to the fact that it is a diurnal mosquito and has ubiquitous mode of feeding. Aedes aegypti is a wellknown vector of yellow fever virus. The presence of these few specimens may not pose any danger now, but continuous monitoring of this environment for Aedes specimens is invaluable to forestall unexpected increase and possibility of yellow fever epidemic.

Parasites detected in blood-fed females Anopheles gambiae was Plasmodium falciparum. This is not surprising that they were found in mosquitoes blood samples from all the six students hostels because it has been the major malaria parasite in the area. These findings agree with the report of Igbeneghu et al. (2012) who reported Plasmodium falciparum as the dominant 
species in Iwo community. Several studies reported high prevalence of $P$. falciparum in different parts of Nigeria. (Babamale and Ugbomoiko, 2016 and WHO, 2017).

Parasites detected in blood-fed females Anopheles gambiae was Plasmodium falciparum. This is not surprising that they were found in mosquitoes blood samples from all the six students hostels because it has been the major malaria parasite in the area. These findings agree with the report of Igbeneghu et al. (2012) who reported Plasmodium falciparum as the dominant species in Iwo community. Several studies reported high prevalence of $P$. falciparum in different parts of Nigeria. (Babamale and Ugbomoiko, 2016 and WHO, 2017).

\section{CONCLUSION}

The study showed that a total of one thousand three hundred and fourty (1341) one mosquitoes were identified and these comprises of five species; Cx. quinquefasciatus $(59.12 \%)$, An. gambiae (22.47\%), An. funestus, $(0.91 \%)$ and Ae. aegypti $(0.18 \%)$. The results showed that majority of the mosquitoes species were fed and therefore control measures aimed at eliminating the breeding sites and reducing its contact with the students so as to minimize disease transmission among the student hostel. Strong emphasis should also be laid on the importance personal protection and environmental hygiene in the student' hostel.

\section{REFERENCES}

Abubakar, A. (2014). Studies on the abundance and distribution of Mosquitoes and prevalence of Malaria in Yabo Local Government Area of Sokoto State, Nigeria. Unpublished MSc. Dissertation. Submitted to Usmanu Danfodiyo University, Sokoto.

Adeleke, .0., Mafiana, M . A., Idowu, C . F., Sam-Wobo, A . B., and Idowu, O.A. (2010 ). Population dynamics of indoor sampled mosquitoes and their implication in disease transmission in Abeokuta, south-western Nigeria. Journal of Vector Borne Disease;47:33-3

Ayanda, O. I. (2009). Relative abundance of adult female anopheline mosquitoes in Ugah, Nasarawa State, Nigeria, Journal of Parasitology and Vector Biology, 1: 005-008.

Babamale, O. A. and Ugbomoiko, U. (2016).Status of malaria infection in peri-urban community of North Central Region of Nigeria. Journal of Bacteriology Parasitolog. 2016;7:256.

Bayoh, M., Walker, E., Kosgei, J., Ombok, M., Olang, G., Githeko, A., Killeen, G., Otieno, P., Desai, M., Lobo, N., Vulule, J., Hamel, M., Kariuki, S. and Gimnig, J. (2014). Persistently high estimates of late night, indoor exposure to malaria vectors despite high coverage of insecticide treated nets. Parasit Vectors 7: 380.

Bechemagbor, A. (2010). Studies on Malaria Prevalence, Drug Treatment Regimes and Intensity of Chloroquine-Resistant Plasmodium Falciparum in Zaria. A Thesis submitted to the School of Postgraduate Studies, Ahmadu Bello University Zaria, Nigeria, in partial fulfilment of the requirement for the award of Master of Science in Zoology Department of Biological Sciences, Faculty of Science, Ahmadu Bello University Zaria, Nigeria.

Centers for Disease Control and Prevention (CDC), (2015). Impact of Malaria. Available at http://www.cdc.gov/ malaria/malaria_worldwide/ impact.html>.

Cheesebrough, M. (2009). District laboratory practice in tropical countries. Part 1.Second edition updated, pp. 245-249. 
Collins, F.H., and Besansky, N.J. (1994). Vector Biology and Control of Malaria in Africa. Science, 264: $1874-1875$.

De Souza D., Kelly-Hope L., Lawson B., Wilson M. and Boakye D. (2010). Environmental factors associated with the distribution of Anopheles gambiae s.s. in Ghana; an important vector of lymphatic filariasis and malaria, PLoS One, 5:24-28.

Ebenezer, A., Okiwelu, S. N., Agi, P. I., Noutcha, M. A. E., Awolola, T. S. and Oduola, A. O. (2012). Species Composition of Anopheles gambiae Complex across ecovegetational zones Bayelsa State, Niger Delta region, Nigreian Journal of Vector Borne Disease.7:164167.

Federal Ministry of Health (FMH), (2013). National Treatment Guidelines Federal Ministry of Health, Publication of the FMH, Nigeria, p. 44.

Gilles, M. T. and Coetzee, M. (1987). A supplement to the Anopheles of Africa South of theSahara.The South Africa Institute of Medical Research, Johannesburg, South Africa. Pp 12 - 79.

Gilles, M. T. and De Mellion, B. (1968). The anopheline of Africa south of the Sahara. Public. South Africa Inst. Med. Res. No 54.

Igbeneghu, C., Igbeneghu, C. and Odaibo, A. B. (2012). Plasmodium species among the inhabitants of iwo community, southwestern Nigeria. American- Eurasian Journal of Scientific Research ;7:118-22.

Levine R. S., Peterson A. T. and Benedict M. Q. (2004). Geographic and Ecological distribution of the Anopheles gambiae complex predicted using a genetic algorithm, American Journal of Tropical Medicine and Hygiene, 70(2): 105-109.

Mbah, C.E., and Egidenda, S.J. (2007). A Survey of Adult Mosquitoes from Some Hospital Buildings in Zaria, Northern Nigeria. Journal of Educational Research and Development, $2(1): 39-46$.

Michael, C. (2014). Abundance of indoor resting mosquito populations and Plasmodium falciparum infection of anopheles spp in settlements around thezaria dam, zaria, kaduna state. a thesis submitted to the school of postgraduate studies, Ahmadu Bello University in partial fulfilment of the requirements for the award of master of science (M.sc.) degree in zoology department of biological science, Ahmadu Bello University, Zaria.

Ndams, I.S. (2004). Morphological and Molecular characterization of Anopheles species and infection of Plasmodium species in parts of Kaduna and Benue state, Nigeria.Ph.dThesis.Department of Biological Sciences, Ahmadu Bello University, Zaria, Nigeria. pp132.

Nwosu L. C., Iwu C. J. and Nwosu U. I. (2011). Assessment of mosquito diversity and evaluation of impact of house treatment with DDT on their population in Amauro, Okigwe L.G.A., Imo State, Nigeria, Journal of Environmental Studies and Management, 4(3): 51-55.

Obembe, M. T. and Awopetu, I. J. (2014). Sporozoite Infection Rate and Identification of the Infective and Refractory Species of Anopheles gambiae(Giles) Complex, Notulae Scientia Biologicae, 6(4): 407-413.

Onyabe D.Y., and Conn J. E. (2001). The Distribution of Two Major Malaria Vectors, Anopheles gambiae and Anopheles arabiensis, in Nigeria, Mem Inst Oswaldo Cruz, 96(8): 1081-1084.

Oyewole I. O., Awolola T. S., Ibidapo C. A., Oduola A. O., Okwa O. O. and Obansa J. A. (2007). Behaviour and population dynamics of the major anopheline vectors in a malaria endemic area in southern Nigeria, Journal of Vector Borne Diseases, 44: 56-64.

Service, M. W. (1980). A Guide to Medical Entomology, Macmillan Press Ltd., pp. 29 - 36. 
Tolle, M. A. (2009). Mosquito-borne diseases. Curr. Probl. Pediatr. Adolesc. Health Care, 4:97-104.

Vontas, J. (2016). Automated innovative diagnostic, data management and communication tool, for improving malaria vector control in endemic settings. Studies in health technology and informatics 224, 54-60.

W.H.O (2017).Vector-borne diseases. Media Center Fact Sheets. Retrieved from http://www.who.int/mediacentre/factsheets/fs387/en/22nd November, 2017.

W.H.O. (2016). World Health Organization. World Malaria Report 2016.

W.H.O. World malaria report (2014). Geneva: World Health Organization; 2014.

WHO/UNICEF news release report, (2015). Malaria MDG target achieved amid sharp drop in cases and mortality, but 3 billion people remain at risk. Available at www.who/ int/ mediacentre/ news/releases/ 2015/ malaria-mdg-target/ en/.Organization Geneva. 